\title{
RTTUR RT
}

Desarrollo turístico y pobreza. El caso del cuzco, Perú

Tourism development and poverty. The case of Cuzco, Peru

Jessica Figueroa Pinedo

jessicafigueroapinedo@gmail.com

Recibido/Received: 05/05/2018

Aceptado/Accepted: 24/07/2018

\section{RESUMEN:}

Este artículo explora la relación entre el turismo y el alivio de la pobreza en regiones pobres en el contexto del desarrollo humano sostenible. El análisis se aplica al caso del Cuzco, el principal destino turístico en el sur andino peruano y una de las regiones más pobres del Perú, particularmente en las áreas montañosas y rurales.

A partir de datos estadísticos disponibles de las fuentes oficiales y estudios inéditos del Observatorio Turístico del Perú, se analiza el entorno socioeconómico regional, el desarrollo de la actividad turística y su impacto en la región. Finalmente, los resultados de la encuesta estadística demuestran que las prácticas turísticas reproducen o profundizan desigualdades socioeconómicas entre la población regional.

Palabras clave: Desarrollo turístico; pobreza; América Latina; desarrollo sostenible; Cuzco; sur andino; Perú.

\section{ABSTRACT:}

This article explores the relationship between tourism and poverty alleviation in poor regions in the context of sustainable human development, using for this purpose the case of Cuzco, the most important tourist destination in the Southern Peruvian Andes and, one of the poorest and vulnerable regions, particularly in the mountainous rural areas. Based on statistical data available from official sources and unpublished studies of the Observatorio Turístico del Perú, I analyse tourism activity in the context of poverty and its socio-economic impact. Finally, the findings suggest that the tourism development reproduces socioeconomic inequalities among the regional population.

Keywords: Tourism development, poverty; Latin America; sustainable development; Cuzco; sur andino; Peru. 


\section{INTRODUCCIÓN}

En los últimos años, el tema de la pobreza ha tomado gran importancia debido al empeoramiento de las condiciones socioeconómicas de muchas poblaciones a nivel mundial y a la enorme desigualdad que experimentan muchos países en América Latina. Cabe resaltar que en lo que se refiere a ese último punto, América Latina es el espacio donde se manifiestan los más altos índices de desigualdad social, es decir donde el gap entre las clases altas y populares es el más marcado (CEPAL, 2017; Sen y Kliksberg, 2007). En ese sentido son numerosos los investigadores y organismos internacionales que se han dedicado a elaborar estrategias, proyectos e investigaciones con la finalidad entender este fenómeno y plantear medidas efectivas y urgentes para resolver este grave problema que afecta a millones de personas en el mundo.

Frente a esta situación, la Organización Mundial de Turismo (OMT, 2004) propone al turismo como una poderosa herramienta para combatir el problema de la pobreza en regiones menos favorecidas y generar ingresos y nuevas fuentes de empleo, principalmente en zonas rurales.

En ese contexto, se han incrementado numerosas experiencias y proyectos relacionados con el turismo de tipo responsable o sostenible en América Latina principalmente en comunidades rurales con poblaciones indígenas que no han logrado un desarrollo económico o industrial importante y por lo tanto sufren de altos índices de pobreza y exclusión social (Gascón y Milano, 2017; Sariego López, 2014; Pérez Galán y Asencio, 2012; Gascón, 2011). Desde esa óptica, el turismo puede representar un motor de desarrollo económico interesante, poniendo en valor la diversidad cultural, el patrimonio y el territorio.

La OMT consagró de alguna manera el tema al asumirlo como uno de sus objetivos privilegiados de estudio. Desde entonces, el análisis del turismo en un contexto de reducción de la pobreza se volvió una de sus prioridades. Por lo tanto, el turismo y la pobreza son hechos socioculturales que están estrechamente vinculados a las mismas circunstancias o participan en los mismos contextos territoriales. Pues, muchas de las prácticas turísticas se desarrollan en zonas o regiones donde los problemas de acceso a los bienes y servicios elementales escasean o donde los niveles de educación, salud e higiene son muy bajos. Sin embargo, son esas regiones o zonas que paradójicamente conservan los medios geográficos más protegidos. Con el desarrollo de la conciencia mundial para la conservación del medio ambiente, las prácticas turísticas buscan esos espacios para disfrutar de zonas consideradas naturales y protegidas. Abundan los ejemplos tanto a nivel mundial como a nivel del Perú.

Lo cierto es que desde sus orígenes, las prácticas turisticas han estado relacionadas con el subdesarrollo y la lucha contra la pobreza. Pero no siempre de la misma manera. Urry (2004) cuenta como se iniciaron los viajes para los obreros del siglo XIX y el impacto de esos tours. Con las huelgas obreras y la creación de los primeros sindicatos, la clase trabajadora exigió vacaciones las cuales permitieron emplear un tiempo de ocio para visitar y conocer nuevas tierras y costumbres. Se crearon los primeros circuitos de "tours" y cada vez más los obreros aprovechaban sus vacaciones para ir más lejos. Actualmente una gran parte de las actividades turísticas tienen como destino países y regiones subdesarrolladas. Son esos lazos entre el subdesarrollo y el turismo que nos interesa analizar.

El Perú resulta ser un caso interesante para este tipo de análisis, pues el turismo internacional creció considerablemente en las últimas décadas, concentrándose en la región sur andina. Una región que posee una gran riqueza cultural y monumental y, a la vez la población presenta 
elevados niveles de pobreza y exclusión social. Además, son extremadamente vulnerables en la medida que pueden estar entrampados en la pobreza y transmitirla a futuras generaciones (Roca Rey y Rojas, 2002).

Partiendo de esta situación, el objetivo de este artículo es analizar y contribuir al debate sobre las posibilidades que tienen las prácticas turísticas de generar desarrollo socioeconómico y prosperidad en regiones menos desarrolladas. Para este fin, echaremos una mirada al caso del Departamento de Cuzco, principal destino turístico en el Perú. A partir de datos estadísticos disponibles de las fuentes oficiales del Perú y datos y estudios inéditos del Observatorio Turístico del Perú (OTP) procedo a una encuesta general sobre las relaciones entre turismo y pobreza en el Departamento de Cuzco. En primer lugar presento la discusión teórica de la pobreza y su relación con el turismo desde una perspectiva multidimensional basándonos principalmente en el enfoque de capacidades de Sen $(1999,2000)$ y, en el contexto peruano, los estudios de Verdera (2007) y Vásquez Huamán, (2004). También cuestiono el discurso triunfalista de los organismos internacionales, liderados por la OMT, de la capacidad de las prácticas turísticas para generar desarrollo sostenible en regiones pobres. Luego presento el caso del Cuzco a través del análisis de datos socioeconómicos y la formación del capital humano, finalmente presento las conclusiones.

\section{LA NOCIÓN DE POBREZA EN EL CONTEXTO DE LAS PRÁCTICAS TURÍSTICAS: UNA APROXIMACIÓN TEÓRICA}

La mayoría de especialista coincide en que la pobreza es un fenómeno multidimensional y complejo de definir porque intervienen múltiples variables y dimensiones. La medición más utilizada se basa en una "línea de pobreza" limite que supone el nivel de ingresos a partir del cual se considera que una persona es pobre. Este procedimiento hace un recuento de las personas que se encuentran bajo la línea de pobreza (Vásquez et al. 2004). Sin embargo, la mayoria de los trabajos en este campo nos dan una idea relativa o parcial de la pobreza limitando su estudio a la falta de ingresos. Por esa razón, algunos autores y organismos internacionales como el Programa de las Naciones Unidas para el Desarrollo (PNUD) consideran que no se trata solamente de un problema de falta de ingresos, sino que incluyen diferentes aspectos que tienen que ver con el desarrollo humano como el acceso a la educación y la salud ${ }^{1}$ (Sen, 1999; Roca Rey y Rojas, 2002; Vásquez Huamán et al. 2004; Vásquez Huamán, 2012; PNUD, 2011).

En el caso peruano, debido a la persistente pobreza que afecta principalmente al área $\mathrm{rural}^{2}$, también se han realizado varias investigaciones y estudios para entender este fenómeno. Por ejemplo, los estudios de Vásquez definen la pobreza como exclusión social: "la ruptura de los lazos que unen a los individuos con su sociedad, como consecuencia de una serie de procesos de marginación y desintegración social que se refuerzan mutuamente". Este enfoque permite

1 En las últimas décadas, debido a la preocupación por el aumento de la pobreza y la desigualdad en el

mundo, se han logrado grandes avances en el marco conceptual del análisis de la pobreza así como un elevado nivel de sofisticación en las herramientas para su medición complementarias al enfoque tradicional (Herrera, 2002).

2 La pobreza total en el Perú experimentó un descenso continuo durante la última década. Según cifras del INEI, la pobreza se redujo de 49,1\% en el 2006 a 20,7\% en el 2016. Sin embargo, según datos de la Encuesta Nacional de Hogares elaborada por el INEI, la pobreza total se incrementó en 1,0\% durante el 2017 respecto al 2016 al pasar de $20,7 \%$ al 21,7\%. En el área rural la pobreza afectó al 44,4\% de la población y en el área urbana $15,1 \%$ de la población. 
conocer aquellos grupos sociales que además de tener bajos ingresos sufren algún tipo de exclusión en los servicios e instituciones propios de su entorno socio-cultural (Vásquez et al., 2004).

La investigación de Verdera (2007) se centra en explorar las causas de la pobreza en el Perú, tanto de la pobreza permanente o estructural como del empobrecimiento reciente, y de las politicas que se han aplicado para reducirla. Verdera pone énfasis en el problema del mercado laboral peruano como una de las principales causas de la pobreza. En primer lugar, porque el mercado no absorbe el exceso de la oferta de trabajo y segundo, los salarios y la calidad del trabajo no permiten a las personas salir de la pobreza. Este punto es importante para una discusión sobre la calidad del empleo que genera el sector turístico.

Hay que tener en cuenta que, en el Perú, el Instituto Nacional de Estadística e Informática (INEI) mide la pobreza bajo el enfoque monetario, es decir, considera como pobres monetarios a las personas que residen en hogares cuyo gasto per cápita es insuficiente para adquirir una canasta básica de alimentos y no alimentos (fijada en 338 soles (unos 103 dólares aproximadamente en el 2017). Una medición muy criticada por desde hace varios años por el economista Farid Matuk. Para Matuk, la medición de la pobreza bajo el enfoque monetario "es una ficción" y, según él, se utiliza en el Perú porque "es la que más reditúa en términos políticos" (El Comercio, 28 de abril 2018). En todo caso, para entender mejor la pobreza en el Perú, Matuk (2010) señala que sería conveniente utilizar el análisis de la pobreza alimentaria, es decir la ingesta de calorias mínimas que requiere una persona $(2,204$ calorias diarias), pues este análisis nos ayuda a comprender mejor la situación real de muchas poblaciones en el Perú y a destinar medidas más eficaces para la erradicación de la pobreza.

Resulta interesante el enfoque teórico de Amartya Sen quien define la pobreza como "el fracaso de las capacidades básicas para alcanzar determinados niveles aceptables" (Sen, 1999:126). E1 enfoque de capacidades de Sen, señala que la pobreza no es sólo un problema de bajos ingresos sino también de la incapacidad de acceder a un nivel aceptable de vida socioeconómica que permita al individuo desarrollar sus "estilos de vida" personales y colectivos (Bonvin y Farvaque, 2008). Por lo tanto, no se debe limitar el estudio de la pobreza solo a la falta de ingresos sino a la privación de las capacidades que permitirian a los individuos participar honesta y cabalmente a la riqueza de la sociedad.

\section{Turismo y lucha contra la pobreza en el Perú}

Hoy el Perú se ha convertido en un destino turístico importante a nivel internacional basado principalmente en el patrimonio histórico-cultural. La llegada de visitantes extranjeros presenta una evolución positiva en las últimas décadas. Según datos del Observatorio Turístico del Perú (OTP) el flujo turístico aumentó de 359.000 en 1988 a 3.731 .472 en el 2017, con una tasa de crecimiento anual de $8,49 \%$ para ese periodo.

El impulso a la actividad turística se dio a partir del Gobierno de Alejandro Toledo (periodo 2001-2006) cuando se recuperó la democracia, se estabilizó la economía y se sentaron las bases para promover el turismo sostenible e inclusivo en el Perú a través del Plan Estratégico Nacional de Turismo (PENTUR 2004-2015). 
En ese contexto, es que surgen muchos proyectos e iniciativas turísticas novedosas que involucran a la población local y están orientadas a desarrollar las capacidades de la población, a través del manejo de negocios en el ámbito rural en el Perú, promovidos por el Estado y organizaciones internacionales, como es el caso del turismo rural comunitario (TRC) con la finalidad de utilizar el turismo como una herramienta de lucha contra la pobreza ${ }^{3} \mathrm{y}$ empoderamiento de las mujeres de comunidades rurales indígenas (Pérez Galán y Fuller, 2015).

Por ejemplo, existen algunas iniciativas ecoturisticas novedosas en comunidades de la amazonia peruana analizados por Stronza (2008) desde la perspectiva etnográfica e identidad cultural y Huata Alfaro (2012) desde el enfoque de desarrollo humano. Es interesante el análisis realizado por Huaita Alfaro (2012) sobre el caso del albergue ecoturístico Posada Amazonas, una empresa que funciona bajo la gestión de una asociación privada entre la compañía Rainforest Expeditions y la Comunidad de Infierno, ubicada en el Departamento de Madre de Dios, demostrando que la actividad turística ha generado nuevas oportunidades para la población local incrementando y potenciando sus capacidades y mejorando su calidad de vida.

En algunas comunidades de Cuzco también se están desarrollando importantes proyectos de turismo en el medio rural como es el caso del agro-turismo del Parque de la Papa con el apoyo de la ONG ANDES que involucra a cinco comunidades del distrito de Pisaq con impactos socioeconómicos muy positivos para la comunidad (Terry, 2017).

Si bien hay propuestas novedosas de turismo gestionado por comunidades como el caso de la isla de Taquile en el Lago Titicaca (Puno), que asumió comunitariamente las tareas relacionadas con las prácticas turísticas y las comparte con todos los miembros de la comunidad. No todos los emprendimientos de TRC han sido exitosos. Por ejemplo, Gascón (2011) analiza el impacto del turismo comunitario en la Isla Amantani (Puno). El autor afirma que el turismo generó conflictos sociales, políticos y religiosos; un reparto desigual de los beneficios y el incremento de la diferenciación campesina.

En esa misma línea, resulta interesante el análisis de Pérez Galán (2012) sobre la relación entre turismo y desarrollo en los Andes concretamente analiza el caso de la red de Turismo Rural Comunitario Pacha Paqareq, y presenta la investigación etnográfica realizada en cinco comunidades quechuas de Cuzco y Puno. Pérez Galán cuestiona el crecimiento de diferentes iniciativas de Turismo Rural Comunitario y su real efectividad frente a la pobreza, pues generan muchas expectativas en las poblaciones rurales indígenas en toda América Latina porque pretenden convertir a los pobres rurales en exitosos empresarios del turismo. Sin embargo, la autora propone que una forma de analizar y concebir este tipo de proyectos es a través de una "mirada antropológica reflexiva" (Pérez Galán, 2012: 173).

Lo que está en juego en muchos de los proyectos en torno a este tema es precisamente la hipótesis general de las posibilidades que poseen las prácticas turísticas de crear espacios de desarrollo sostenible. De igual manera, se tiene por hipótesis que los recursos naturales y culturales o patrimoniales en general, son objetos que atraen la demanda regional o mundial del mercado de esparcimiento tanto para fines vacacionales y anodinos como para conocer la historia o las experiencias culturales vividas en territorios que son ajenos al entorno cotidiano (llámese turismo cultural). El punto de partida es pues la idea de un mercado que fácilmente

\footnotetext{
3 Según el Ministerio de Comercio Exterior y Turismo (Mincetur) existen en total 76 emprendimientos de TRC en 16 regiones del Perú (www.mincetur.gob.pe).
} 
consume ese tipo de bienes, es decir naturaleza y patrimonio. Resulta pues, en estas circunstancias, que un país como el Perú responde a las exigencias de esa hipótesis general.

Si bien los casos mencionados anteriormente ilustran los impactos positivos así como los conflictos que genera el turismo en comunidades rurales, son iniciativas aisladas. Por lo tanto, es importante un análisis global de la relación entre las prácticas turísticas y su aporte al desarrollo socioeconómico de las poblaciones locales. A continuación, presentamos el caso del Cuzco.

\section{DESARROLLO TURÍSTICO Y POBREZA EN EL DEPARTAMENTO DE CUZCO}

El Departamento del Cuzco está situado al sureste del Perú, su territorio abarca desde las altas cumbres andinas hasta la selva, dividido administrativamente en 13 provincias. La región concentra una enorme riqueza patrimonial, cultural y gran parte del legado de la cultura inca y colonial. Cuzco posee atractivos turísticos de fama internacional como es el caso del Santuario Histórico de Machu Picchu, símbolo de las culturas prehispánicas de América del Sur. La ciudad del Cuzco y Machu Picchu fueron declarados Patrimonio de la Humanidad en 1983 por la UNESCO principalmente por su riqueza cultural y natural, que cada año atrae a un gran número de visitantes internacionales procedentes principalmente de Norte América y de Europa. Por lo tanto, Cuzco junto con Machu Picchu situado en el corazón del Imperio Inca se convirtió en el centro del turismo en el Perú (Ver Figura 1).

Figura 1: Mapa turístico del Departamento de Cuzco

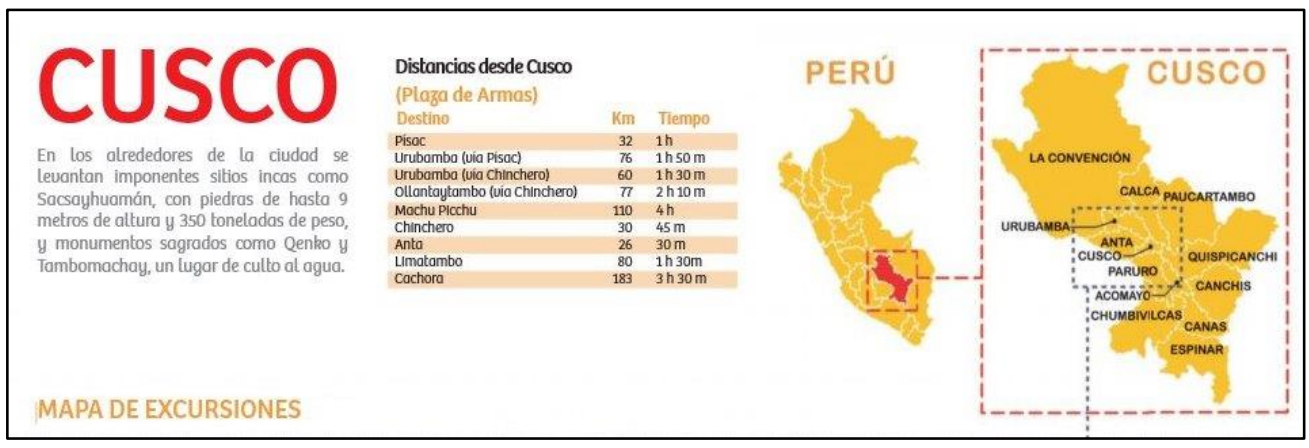




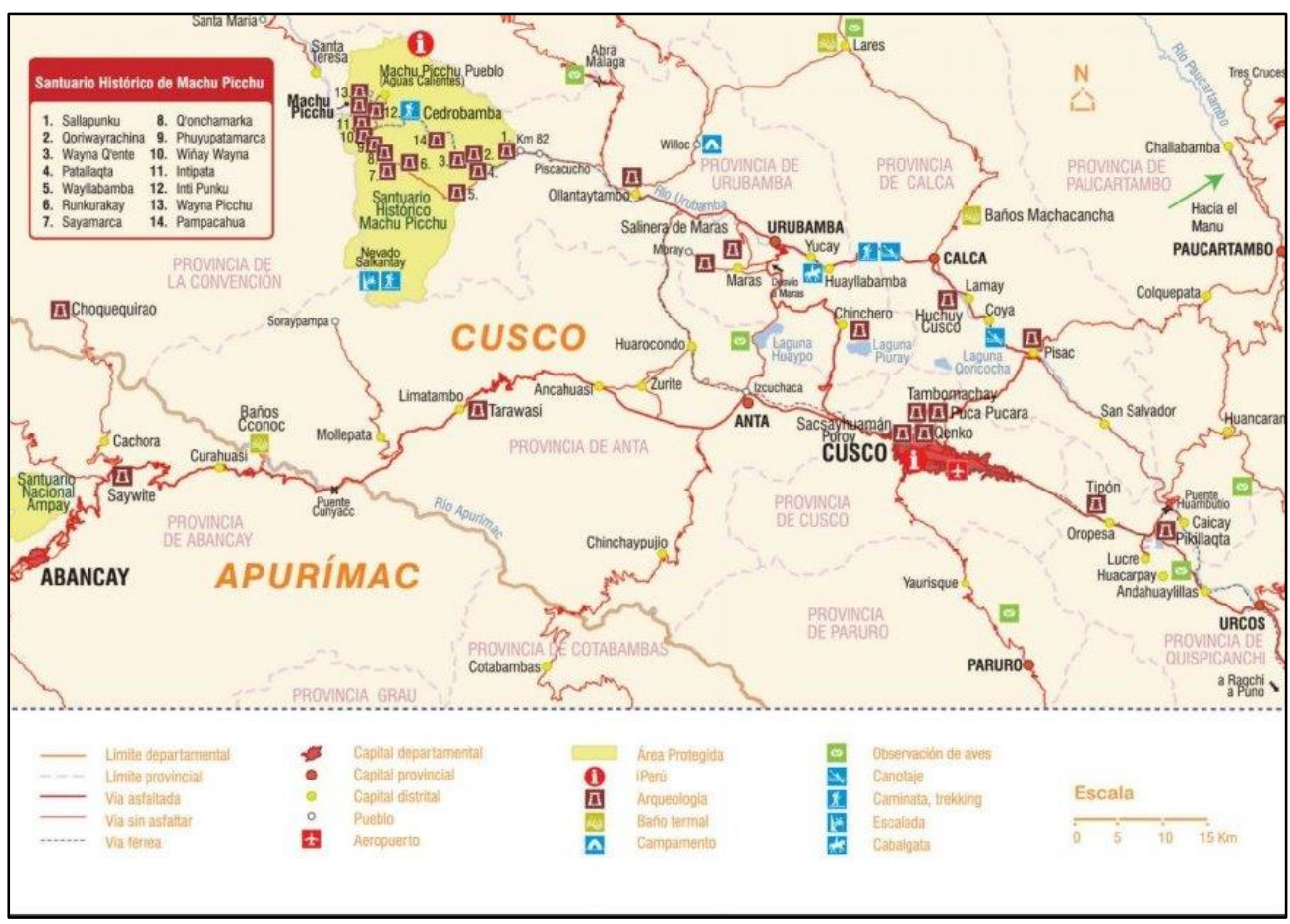

Fuente: PROMPERÚ

La región ha experimentado una serie de cambios sociales y económicos desde la década de 1960 cuando se dio impulso al desarrollo turístico a través del Plan COPESCO ${ }^{4}$. Añádase a esos hechos que, a partir de 1944, el notable esfuerzo de la ciudad para llamar la atención de la mirada turística para sus riquezas patrimoniales. La Semana del Cuzco que, aún hoy día se celebra, fue el inicio de una próspera y continuada marcha de reconocimiento internacional.

Hay algunas lecciones que se pueden sacar de la experiencia de Cuzco y de su entorno. Se olvida que la presencia de Cuzco en el mapa del turismo receptivo presenta características propias. Recordaré algunas: 1.- Cuzco y Machu Picchu posee un siglo de publicidad por el interés que despertaron sus ruinas a inicios del siglo XX; 2.- Coincidió ese hecho con el desarrollo de la vía férrea que facilitó el acceso de los países del sur a las tierras del altiplano. De igual manera, la vía férrea facilitó el acceso al Cuzco y a los bienes patrimoniales incaicos. Esos dos hechos, cambiaron completamente el paisaje turístico del Cuzco. Todo ello contribuyó al rápido crecimiento de la infraestructura turística, los numerosos hoteles de lujo, restaurantes de comida internacional y la existencia del valle del Cuzco que, en los últimos años, desarrolló numerosos proyectos hoteleros que albergan una población más estable en el valle, transformaron la ciudad y la región en una plaza mundialmente conocida.

\footnotetext{
4 En el Perú, la inversión orientada a impulsar la actividad turística a través de la creación de infraestructura y servicios turístico se concentró inicialmente en la década de 1960 y 1970 mediante el Plan COPESCO (Comisión PerúUNESCO) con la finalidad de implementar un programa turístico en el circuito sur andino, una región muy pobre pero con importantes atractivos turísticos. A través de este plan se invirtió en infraestructura, se restauraron monumentos, se mejoró la red vial y los servicios básicos (Tello Rozas y Paredes Izquierdo, 2002:44).
} 
No cabe duda que las inversiones turísticas generaron un impacto favorable en la región pues tenían como finalidad generar desarrollo económico, crear empleo y reducir la pobreza en la región, apoyados en el principio discursivo empleado por los organismos internacionales en el campo de las practicas turísticas. A pesar de las grandes promesas, el sector turístico cuzqueño presenta actualmente graves problemas de gestión del espacio principalmente en Machu Picchu generando un aumento de conflictos sociales, informalidad, contaminación y desigualdades sociales (Figueroa et al. 2015; Zan y Lusiani, 2011; Arellano, 2011; Martorell, 2000).

\section{Población y diversidad geográfica}

El Departamento de Cuzco tiene una población total de 1.316.729 habitantes, una de las más importantes del sur andino. La variedad geográfica corresponde también a una gran diversidad de poblaciones y de géneros de vida. En alta montaña viven las poblaciones consagradas al pastoreo de altura, generalmente muy aisladas, mientras las de los valles, precisamente las del valle del Cuzco, son muy dinámicas y activas en lo que se refiere a la agricultura y, en los últimos treinta años, a las actividades turísticas y artesanales.

Los datos de la Tabla 1 muestran la evolución de la población del departamento de Cuzco. Según el INEI, la tasa de crecimiento poblacional registrada en el último censo de 2007 es de 0.9\% anual, la más baja desde los censos de 1940 y por debajo del promedio de crecimiento a nivel nacional $(1,6 \%)$. Se constata también, la disminución de la población en el ámbito rural de $74,8 \%$ en 1940 a $44,5 \%$ en 2015 , ello evidencia una concentración cada vez mayor en el ámbito urbano.

Tabla 1: Evolución de la población en el Departamento de Cuzco 1940-2015

\begin{tabular}{|c|c|c|c|c|c|}
\hline Año & Total & Urbana & $\%$ & Rural & $\%$ \\
\hline 1940 & 486,592 & 122,552 & 25,2 & 364,040 & 74,8 \\
\hline 1961 & 611,972 & 198,341 & 32,4 & 413,631 & 67,6 \\
\hline 1972 & 715,237 & 262,822 & 36,7 & 452,415 & 63,3 \\
\hline 1981 & 832,504 & 348,396 & 41,8 & 484,108 & 58,2 \\
\hline 1993 & $1,028,763$ & 471,725 & 45,9 & 557,038 & 54,1 \\
\hline 2007 & $1,171,403$ & 644,684 & 55,0 & 526,719 & 45,0 \\
\hline $2015^{*}$ & $1,316,729$ & 731,284 & 55,5 & 585,445 & 44,5 \\
\hline
\end{tabular}

Fuente: INEI -Censos Nacionales 1940, 1961, 1972,1981, 1993, 2007

*Población proyectada INEI

Hay factores que incidieron en la disminución de la población rural cuzqueña que son hoy día aceptados por los estudios socioeconómicos sobre la región. Nadie duda, por ejemplo, de la influencia capital de los ensayos de reforma agraria de los años 1960 y luego de la reforma agraria del gobierno de General Velasco, a inicios de los años 1970. Con esas medidas, algunas de ellas bastante radicales, el agro tradicional peruano se hundió y perdió sus anteriores características, fundamentalmente basadas en la estructura de la hacienda. Al derrumbarse 
ese sistema, muchas familias abandonaron la región y aprovechando sus ahorros y bienes buscaron en la ciudad lo que el campo les negaba.

A esos factores, hay que añadir los trágicos años de terrorismo que causaron graves daños en toda la región sur andina ${ }^{5}$. En cuanto al desarrollo turístico en Cuzco, hay preponderancia del factor urbano sobre los espacios rurales, pues las actividades turísticas se concentran en medios urbanos o ligados a ellos estrechamente. Es en la ciudad de Cuzco, capital de la región, desde dónde se organizan las actividades y servicios turísticos para toda la región.

\section{Prácticas turísticas en el espacio económico local}

Según datos del Observatorio Turístico del Perú (OTP), el turismo extranjero y nacional hacía Cuzco se ha incrementado considerablemente en las últimas décadas, pasando de 242.264 en 1992 a 1.408 .146 en el 2015. El turismo receptor demostró un crecimiento medio anual de $14,19 \%$ mientras que el turismo nacional creció 3,58\% (Ver Tabla 2).

Tabla 2: Evolución de turistas en Cuzco 1992-2015

\begin{tabular}{|l|l|l|l|}
\hline \multicolumn{1}{|c|}{ Año } & \multicolumn{1}{|c|}{$\begin{array}{c}\text { Turistas } \\
\text { extranjeros }\end{array}$} & \multicolumn{1}{c|}{$\begin{array}{c}\text { Turistas } \\
\text { nacionales }\end{array}$} & \multicolumn{1}{c|}{ Total } \\
\hline 1992 & 45734 & 196530 & 242264 \\
\hline 1993 & 69173 & 228118 & 297291 \\
\hline 1994 & 131536 & 256913 & 388449 \\
\hline 1995 & 173894 & 254795 & 428689 \\
\hline 1996 & 216758 & 247415 & 464173 \\
\hline 1997 & 218752 & 248963 & 467715 \\
\hline 1998 & 269762 & 227204 & 496966 \\
\hline 1999 & 330349 & 232070 & 562419 \\
\hline 2000 & 361211 & 218483 & 579694 \\
\hline 2001 & 410448 & 233084 & 643532 \\
\hline 2002 & 366325 & 249908 & 616233 \\
\hline 2003 & 455249 & 241542 & 696791 \\
\hline 2004 & 491822 & 242504 & 734326 \\
\hline 2005 & 528394 & 243466 & 771860 \\
\hline 2006 & 564967 & 244428 & 809395 \\
\hline 2007 & 601540 & 245390 & 846930 \\
\hline 2008 & 638112 & 246351 & 884463 \\
\hline
\end{tabular}

\footnotetext{
${ }^{5}$ La década de los años 1980 fue terrible y desarticuló lo que aún restaba de organización campesina tradicional y los ensayos de vida cooperativa difundidos en los años 1970.
} 


\begin{tabular}{|l|l|l|l|}
\hline 2009 & 614374 & 247313 & 861687 \\
\hline 2010 & 517123 & 248275 & 765398 \\
\hline 2011 & 674685 & 325876 & 1000561 \\
\hline 2012 & 775423 & 408765 & 1184188 \\
\hline 2013 & 820979 & 420987 & 1241966 \\
\hline 2014 & 857548 & 421200 & 1278748 \\
\hline 2015 & 967266 & 440880 & 1408146 \\
\hline
\end{tabular}

Fuente: Observatorio Turístico del Perú (OTP)

Es evidente que Cuzco ejerce un gran poder de atracción tanto para el turista extranjero como el nacional. La declaración de Machu Picchu como una de las Maravillas del Mundo en julio de 2007 significó una mayor presión por visitar este monumento y una mayor publicidad para la región. Este espectacular aumento del turismo también se refleja en el crecimiento del sector hotelero cuzqueño. De acuerdo a los datos de la Tabla 3, el número de hoteles (clasificados y no clasificados) pasó de 666 hoteles en 2003 a 1979 en 2016.

En general, la planta turística en el Perú muestra una estructura productiva segmentada; por una parte, conformada por una limitada y creciente participación de grandes cadenas hoteleras que brindan servicios con altos estándares de calidad; y por otra parte, una mayoría de pequeñas unidades productivas con bajos estándares de calidad (MTPE, 2013:9).

Tabla 3. Evolución del número de hoteles en Cuzco 2003-2016

\begin{tabular}{|c|c|c|c|}
\hline Año & $\begin{array}{c}\text { Clasificados (hoteles } \\
\text { de 1 a estrellas) }\end{array}$ & No clasificados & Total \\
\hline 2003 & 164 & 502 & 666 \\
\hline 2004 & 162 & 536 & 698 \\
\hline 2005 & 155 & 584 & 739 \\
\hline 2006 & 134 & 675 & 809 \\
\hline 2007 & 118 & 762 & 880 \\
\hline 2008 & 102 & 929 & 1031 \\
\hline 2009 & 103 & 1006 & 1109 \\
\hline 2010 & 128 & 1041 & 1169 \\
\hline 2011 & 171 & 1074 & 1245 \\
\hline 2012 & 195 & 1119 & 1314 \\
\hline 2013 & 224 & 1204 & 1428 \\
\hline 2014 & 258 & 1384 & 1642 \\
\hline 2015 & 258 & 1630 & 1888 \\
\hline 2016 & 261 & 1718 & 1979 \\
\hline
\end{tabular}


Fuente: Datos obtenidos del Ministerio de Comercio Exterior y Turismo (MINCETUR)

Por otro lado, Cuzco ha sido la segunda región con mayor crecimiento económico en el Perú. De acuerdo a los datos del INEI, el crecimiento del PBI del Departamento de Cuzco entre el 2007 y 2016 ha sido extraordinario, El PBI ha pasado de 10.913.725 en el 2007 a 21.829.280 millones de soles en el 2016.

En relación al sector turismo (alojamientos y restaurantes) de Cuzco, según datos del INEI, el PBI ha aumentado sostenidamente en los últimos años pasando de 497.564 millones de soles en el 2007 a 888.715 millones de soles en el 2016. Sin embargo, el porcentaje de participación en el PBI regional ha disminuido pasando de 4,6\% en el 2007 a 4,1\% en el 2016 (ver Tabla 4).

Tabla 4: Aporte del sector turismo al PBI del Departamento de Cuzco

(Valores en soles a precios constantes del 2007)

\begin{tabular}{|c|c|c|c|}
\hline Año & $\begin{array}{c}\text { PBI Cuzco (Miles } \\
\text { de soles) }\end{array}$ & $\begin{array}{c}\text { PBI Turismo } \\
\text { (alojamiento y } \\
\text { restaurant } \\
\text { (Miles de soles) }\end{array}$ & $\begin{array}{c}\text { Participación } \\
\text { del sector } \\
\text { Turismo (\%) }\end{array}$ \\
\hline 2007 & 10.913 .725 & 497.564 & 4,6 \\
\hline 2016 & 21.829 .280 & 888.715 & 4,1 \\
\hline
\end{tabular}

Fuente: INEI

Ello se explica por el espectacular crecimiento de la mineria, con la extracción de gas y minerales, convirtiéndose en el sector productivo líder que ha dado un mayor impulso a la economía regional aportando un 49\% al PBI regional; seguido por el sector construcción que también ha logrado una importante contribución a la economía, tal como se aprecia en la Tabla 5. Por consiguiente, si bien las actividades relacionadas al turismo tienen un peso significativo en la economía cuzqueña, los datos demuestran que no es la principal actividad que contribuye a generar riqueza en la región. Mientras que la agricultura, en los últimos años, ha mostrado una baja productividad contribuyendo sólo un 5\% en el 2016. Teniendo en cuenta la región es una de las principales zonas agrícolas del país y el 18\% de la PEA de Cuzco $(138,000$ trabajadores en el 2012) se encuentra en el sector agrícola (IPE, 2014). 
Tabla 5. PBI Cuzco por sectores económicos, 2016

\begin{tabular}{|c|c|c|}
\hline Actividades & $\begin{array}{c}\text { Valor Agregado } \\
\text { Bruto (miles de } \\
\text { soles) }\end{array}$ & $\begin{array}{c}\text { Estructura } \\
\%\end{array}$ \\
\hline Agricultura, Ganaderia, Caza y Silvicultura & 1.025 .706 & 5 \\
Pesca y Acuicultura & 770 & 0 \\
Extracción de Petróleo, Gas y Minerales & 10.746 .372 & 49 \\
Manufactura & 1.082 .606 & 5 \\
Electricidad, Gas y Agua & 253.989 & 1 \\
Construcción & 1.503 .702 & 7 \\
Comercio & 1.529 .722 & 7 \\
Alojamiento y Restaurantes & 889.216 & 4 \\
Telecom. y Otros Serv. de Información & 888.715 & 4 \\
Administración Pública y Defensa & 484.937 & 12 \\
Otros Servicios & 799.568 & 4 \\
Valor Agregado Bruto & 2.623 .977 & 12 \\
\hline
\end{tabular}

Fuente: INEI

En relación al empleo en el sector turístico de la región, los datos del Ministerio de Trabajo y Promoción del Empleo (MTPE) señalan que el número de trabajadores aumentó de 38.793 mil trabajadores en el 2004 a 47.375 mil trabajadores en el 2011, con una participación del 6.6\% en el empleo total de la región para el 2011 (MTPE, 2013). Ello significa, por lo tanto, una baja participación en el empleo total de la región de Cuzco. Asimismo, este organismo afirma que el empleo en la actividad turística en el Perú se caracteriza por ser de baja calidad, centrado en el autoempleo y en pequeñas unidades productivas.

\section{Desarrollo y pobreza}

El análisis de los flujos turísticos hacia Cuzco nos indicaba un desarrollo favorable de las actividades turísticas, en los últimos años, además la región de Cuzco presenta un crecimiento económico por el auge del sector minero e hidrocarburos que está generando importantes ingresos para la región. Sin embargo, la disminución de la pobreza no ha sido tan espectacular. La Tabla 6 muestra la evolución de la pobreza total estimada por el INEI. Entre el 2006 y 2008 la pobreza aumentó de $49,9 \%$ a $58,4 \%$, a pesar de que a partir del 2004 la región empezó a 
recibir importantes ingresos provenientes de la explotación minera. Ello se explica por los efectos perjudiciales de las condiciones climáticas que afectaron la agricultura en el valle del Cuzco, principalmente en las provincias altas, que son precisamente, las más pobres (Banco Central de Reservas del Perú, 2009:32). Posteriormente se observa importantes avances en reducción de la pobreza entre el 2008 y 2013, de $54,8 \%$ a $18,8 \%$. También se constata que la reducción de la pobreza no ha sido continua pues se observa un aumentó en 4,8 puntos porcentuales en el 2017 respecto al año anterior. De hecho, Cuzco fue la región donde más creció la pobreza durante el 2017 (de los 24 departamentos del Perú). Esos datos nos demuestran que el crecimiento económico de la región no ha tenido un impacto en mejorar las condiciones de vida de las personas.

Tabla 6: Departamento de Cuzco: Pobreza monetaria total

\begin{tabular}{|c|c|}
\hline Años & $\begin{array}{c}\text { Pobreza total } \\
\%\end{array}$ \\
\hline 2004 & 53,1 \\
\hline 2005 & 55,6 \\
\hline 2006 & 49,9 \\
\hline 2007 & 57,4 \\
\hline 2008 & 58,4 \\
\hline 2009 & 51,1 \\
\hline 2010 & 49,5 \\
\hline 2012 & 25,1 \\
\hline 2013 & 18,8 \\
\hline 2015 & 17,6 \\
\hline 2016 & 20,4 \\
\hline 2017 & 25,2 \\
\hline
\end{tabular}

Fuente: INEI $(2017,2018)$

Ahora bien, la reducción de la pobreza entre el 2010 y 2015 ha tenido mayor incidencia en el área urbana mientras que en el área rural la pobreza sigue latente. Según el Mapa de pobreza provincial y distrital 2013, elaborado por el INEI (2015), la provincia del Cuzco presenta una menor incidencia de la pobreza, precisamente el distrito de Wanchaq es el menos pobre de la región inferior al 0,9\%, mientras que las provincias altas, por ejemplo, en Paucartambo la pobreza es mayor al 30\%. Lo cual demuestra fuertes contrastes y una marcada desigualdad en la distribución de la riqueza regional.

Por otro lado, si tomamos como referencia la pobreza alimentaria los resultados son interesantes porque la pobreza alimentaria se incrementó considerablemente en la región de Cuzco de 24\% a 34\% entre 2006 y 2009 (superior al promedio nacional de 28\%), es decir en 10 puntos porcentuales (Matuk, 2010). 
Si analizamos otros indicadores sociales veremos que Cuzco enfrenta preocupantes problemas de desarrollo. En cuanto a la salud ocupa el puesto 14 de 24 regiones, debido a sus preocupantes indicadores en este sector. En primer lugar, según la Encuesta Nacional de Hogares del INEI, la mortalidad en la niñez es elevada (30 muertes por cada 1,000 nacidos en el 2014). Esta cifra supera el promedio nacional de 23. La desnutrición crónica es un problema persistente que golpea principalmente a los niños menores de 5 años con un 16,7\% en 2015, superior al promedio nacional de14,4\% (Ver Tabla 7). En el caso de la anemia en niños menores de 5 años las cifras son preocupantes porque se incrementó de $41.7 \%$ en el 2015 a $46,8 \%$ en el $2016^{6}$, lo cual evidencia un grave problema de salud pública. En relación a la tasa de analfabetismo no hubo grandes progresos, se observa una leve disminución de $12,1 \%$ en el 2007 a $11.5 \%$ en el 2015; una tasa superior al promedio nacional (6\%) tal como se puede ver en la Tabla 7.

Tabla 7: Principales indicadores sociales del Departamento de Cuzco y Perú

\begin{tabular}{|c|c|c|}
\hline & Cuzco & Perú \\
\hline $\begin{array}{c}\text { Tasa de desnutrición crónica niños } \\
\text { menores de 5 años (\%) }\end{array}$ & & \\
2009 & 38,4 & 23,8 \\
2015 & 16,7 & 14.4 \\
\hline $\begin{array}{c}\text { Tasa de analfabetismo de 15 a más años de } \\
\text { edad (\%) }\end{array}$ & & \\
2007 & 12,1 & 8,5 \\
2015 & 11,5 & 6 \\
\hline Anemia en niños menores de 5 años (\%) & & 43,5 \\
2015 & 41,7 & 43,6 \\
2016 & 46,8 & \\
\hline vivos & & 23 \\
\hline
\end{tabular}

Fuente: INEI-Encuesta Nacional de Hogares (ENAHO). IPE (2015; 2018).

Las estadísticas oficiales analizadas demuestran que Cuzco no es una región competitiva en términos de desarrollo social, demostrando aún graves problemas de en salud y educación que afectan a la población y reflejan los grandes desafios en términos de desarrollo humano.

6 Las provincias con mayor porcentaje de anemia en niños son: Quispicanchi, Espinar, Paucartambo, Cuzco y Acomayo. Llama la atención que siendo Cuzco, capital del departamento, y la menos pobre sea una de la más afectada por la anemia. 


\section{Inversión pública}

Cuzco es una de las regiones peruanas con más recursos para la inversión pública, pues reciben el canon procedente de la explotación minera. De hecho, desde el 2004 a la fecha (incluye el presupuesto del 2018) se ha realizado una fuerte inversión pública de casi 80 mil millones de soles en los tres niveles de gobierno (nacional, regional y municipal) (La República, 30 de abril 2018).

El problema de Cuzco es que no tiene un eficiente nivel de ejecución del gasto público y la incapacidad de los gobiernos (regional y municipal) para ejecutar proyectos de inversión que respondan a las necesidades de desarrollo de la región (Guzmán Sánchez et al, 2006). Por ejemplo, en el 2016, el gobierno regional de Cuzco alcanzó un nivel de ejecución del 67\%, cifra inferior con respecto al 2015 el cual fue de $81 \%$. Acumulando un total de 208 millones de soles sin ejecutarse en el 2016 (Gestión, 2017).

El destino de las inversiones por parte del Gobierno Nacional en dicho periodo ha sido principalmente en el sector transporte y comunicaciones que representa el 50\% del gasto total, mientras que en el ámbito de desarrollo social se ha destinado sólo el 18\%. El Gobierno Regional ha priorizado el gasto en el sector agrario y el Plan COPESCO (infraestructura asociada al desarrollo turístico) que ha invertido 53 millones de soles. El Gobierno Local también ha destinado gran parte de la inversión en la construcción y mejoramientos de carreteras y vías urbanas, así como edificaciones escolares y centros deportivos. La misma situación se presenta durante el periodo 2012-2016, la mayor ejecución de gastos fue del Gobierno Regional de Cuzco fue en obras de infraestructura y no tanto en previsión social y mejorar la calidad de la educación.

Según un informe publicado en La República varios especialistas coinciden en el mal uso del dinero procedente del canon minero en obras que no han sido prioritarias para la región, además de la corrupción y excesiva burocracia. También señalan la paralización de grandes proyectos importantes como el Aeropuerto Internacional de Chinchero, el Hospital Antonio Lorena $^{7}$ (en la ciudad de Cuzco) y principales vias regionales (La República, 30 abril 2018).

Llama la atención que los tres niveles de Gobierno en la región de Cuzco hayan invertido un mayor porcentaje en el sector transporte y comunicaciones mientras que el sector educación y desarrollo social no le hayan dado mayor prioridad. El Gobierno Regional ha destinado en total el $18,8 \%$ al sector educación y cultura y dentro de esta rama, sólo el 1\% a la capacitación y entrenamiento del recurso humano (Grupo Propuesta Ciudadana, 2009). La inversión se concentró en la construcción de instituciones educativas más que en mejorar la calidad educativa. Esta situación nos lleva a comprobar la falta de una redistribución equitativa y diversificada en el gasto público, enfocada en el desarrollo de capacidades de la población y en sectores intensivos en mano de obra (como es el caso del turismo y la agricultura). No se trata sólo de dar ayudas o caridad a la población a través de los programas sociales sino de invertir en incrementar sus capacidades (en educación y salud) de forma que puedan insertarse en el mercado laboral y aprovechar las oportunidades del crecimiento económico.

\footnotetext{
7 La obra se inició en julio de 2012 y hasta la fecha (2017) no se ha logrado concluir el proyecto debido a las irregularidades y falta de capacidad de los gobiernos regionales. http://larepublica.pe/sociedad/1096377-el-viacrucis-para-construir-el-hospital-antonio-lorena-de-cusco
} 


\section{Capital humano en el espacio turístico cuzqueño}

Se ha constatado el ineficiente uso de los recursos públicos en el progreso social y la inversión en capital humano en la región cuzqueña. Teniendo en cuenta que, como sostiene Sen (2000) la formación del capital humano acompaña el crecimiento económico y permite crear las condiciones propicias para el desarrollo sostenible. En ese contexto, las poblaciones rurales de la región laissées pour compte presentan enormes deficiencias y no pueden entrar ni aprovechar de un desarrollo de las prácticas turísticas en el sentido cabal de la expresión.

A partir de los estudios realizados por el Observatorio Turístico del Perú (OTP) en el 2009 (Urbano et al. 2010) sobre la brecha entre la oferta y la demanda en el sector de los recursos humanos en el sector hotelero de Cuzco, proporcionan algunas pistas que nos permiten desprender del discurso ideológico del turismo los hechos que definen las desigualdades de condición social y no sólo las financieras o económicas.

De acuerdo con los datos del OTP, La región de Cuzco cuenta con 16 instituciones dedicadas a la formación de la mano de obra en el sector turístico y hotelero (de los cuales 4 corresponden a universidades y 12 a institutos o escuelas de formación no universitaria). El número total de profesionales que salen al mercado son en promedio 480 cada año (180 universitarios y 300 técnicos).

Durante la investigación el OTP realizó una encuesta a los responsables de las empresas hoteleras (226 hoteles de 3 a 5 estrella). El 94,44\% de los encuestados opina que los egresados de institutos superiores tienen competencias mínimas necesarias para desempeñarse adecuadamente en un puesto del sector hotelero. Sin embargo, cuando se les preguntó por competencias profesionales de los egresados de Turismo para aplicar a un puesto en el hotel que demanda competencias laborales específicas el 100\% de los encuestados afirmó que los candidatos de Cuzco no tienen las competencias necesarias.

Otro resultado importante es que las empresas hoteleras desconocen o no tienen la información correcta sobre la oferta profesional por parte de las universidades e institutos, según la totalidad de los encuestados. De ahí, la conclusión obvia: no hay una conexión entre las instituciones educativas y la demanda de las empresas hoteleras que puedan encaminar los recursos humanos locales hacia los centros de trabajo donde ellos hipotéticamente deberian encontrar trabajo. El divorcio entre los dos es prácticamente total.

En cuanto a la capacitación al personal contratado que ingresa a trabajar a los hoteles de 5, 4 y 3 estrellas de la ciudad de Cuzco, los responsables hoteleros encuestados afirman que las áreas que más demandan personal y capacitación es housekeeping, las áreas de recepción y restaurantes. Es decir, los empleados que por lo general no son calificados.

Ahora bien, lo más significativo de esos datos estadísticos es la existencia de una oferta educativa de baja calidad que procede de las instituciones de educación superior encargadas de la formación en Turismo y Hotelería. En otras palabras, los profesionales que egresan con diplomas de educación superior universitaria o institutos profesionales no responden a la demanda laboral, principalmente en puestos que exigen una mayor preparación académica y más exigentes normas profesionales. No se da pues una adecuada relación y coordinación entre los requerimientos de las empresas hoteleras y turisticas de la región de Cuzco y las instituciones educativas que forman profesionales en Hotelería y Turismo.

En ese sentido, no existe en la región de Cuzco un proceso de formación del capital humano que permita a los individuos insertarse de manera adecuada y formal en la oferta laboral del mercado hotelero y turístico. Por lo tanto, esos profesionales conformarian parte del segmento de mano de obra poco calificada y mal remunerada. De ahí, la consecuencia inevitable: los puestos ejecutivos son ocupados por profesionales exteriores a la región cuzqueña. Estando pues las cosas en ese pie, queda patente la inevitable distorsión en el mercado de mano de 
obra, la cual priva los grupos locales de profesionales de acceder a la riqueza generada por las prácticas turísticas y hoteleras. En lugar de tener la oportunidad de compartir un mercado laboral competente y sólidamente instalado, el sistema educativo universitario y profesional relega hacia puestos de poca incidencia económica y financiera o a la informalidad laboral.

\section{CONCLUSIONES}

El caso del Cuzco es, pues de una gran riqueza en términos de lecciones teóricas y prácticas sobre el quehacer turístico. Se ha constatado la existencia de un flujo turístico indiscutible y abundante coexiste con altos porcentajes de pobreza. Incluso hemos subrayado que la pobreza aumentó recientemente pese al espectacular crecimiento económico de la región.

Por la importancia que tiene el eje Cuzco/Machu-Picchu en el discurso histórico y simbólico del departamento se podía creer que las prácticas turísticas ocupan el primer lugar en el conjunto de contribuciones porcentuales al PBI regional. Nuestro análisis estadístico demuestra que la explotación de recursos minerales e hidrocarburos figura en el primer lugar en la contribución de riqueza regional.

Los flujos de población que las prácticas turísticas deberian hipotéticamente demandar y absorber no se dan o por lo menos funcionan con muchas deficiencias. Y la razón es obvia: los niveles de educación y salud del Departamento de Cuzco no desarrollan las capacidades personales e individuales mencionadas en los estudios de Sen $(1999,2000)$ para ocupar en el mercado de trabajo capitalista puestos productivos y económicamente estables. Esta situación nos lleva a pensar que las prácticas turísticas no han podido hasta ahora equilibrar los desajustes socioeconómicos provocados por la existencia de una población marginada y pobre. Los resultados de la encuesta estadística son suficientemente explícitos para poner en duda ese principio discursivo empleado por los organismos internacionales en el campo de las prácticas turísticas, que el turismo genera desarrollo, como discurso universal.

\section{REFERENCIAS BIBLIOGRÁFICAS}

Arellano, A. (2011). "Tourism in poor regions and social inclusion: the porters of the Inca Trail to Machu Picchu". World Leisure Journal, 53 (2):104-118.

Banco Central de Reservas del Perú. (2009). Informe económico y social: Región Cusco. Lima: BCRP.

Bonvin, J. M. y Farvaque, N. (2008). Amartya Sen: Une politique de la liberté (Le bien commun). Paris: Michalon.

CEPAL. (2017). Panorama Social de América Latina 2016. Santiago de Chile: Naciones Unidas, CEPAL.

El Comercio (28 de abril 2018). "Farid Matuk: "La pobreza es una ficción; la anemia, no" Recuperado el 28 de abril 2018 de

https://elcomercio.pe/somos/farid-matuk-pobreza-ficcion-anemia-noticia-515599

Figueroa Pinedo, J. (2014). Turismo, pobreza y desarrollo sostenible. Los casos de Cuzco, Cajamarca y La Libertad, (Tesis Doctoral), Universidad de Girona.

Figueroa, J., Arellano, A. y Tello, S. (2015). "Développement touristique ou reproduction sociale de la pauvreté: Les leçons de Cuzco, Pérou", Téoros, 33(2).

Gascón, J., y Milano, C. (Coord.) (2017). El turismo en el mundo rural. ¿Ruina o consolidación de las sociedades campesinas $e$ indigenas? Tenerife y Barcelona: PASOS; RTPC; Foro de Turismo Responsible; Ostelea. 
Gascón, J. (2011). “Turismo rural comunitario y diferenciación campesina. Consideraciones a partir de un caso andino". Mundo Agrario, 11 (22). http:/ / www.memoria.fahce.unlp.edu.ar/art_revistas/pr.4785/pr.4785.pdf

Gestión (2017). "Sepa cuánto dejaron de invertir las regiones en el 2016". Gestión, 5 de enero. Recuperado el 5 de enero de 2017, de https://gestion.pe/economia/sepa-dejaroninvertir-regiones-2016-125979

Grupo Propuesta Ciudadana (2009). Gasto público y canon en el Perú. Análisis y recomendaciones para el mejor aprovechamiento de las rentas del Gas de Camisea, Lima: Grupo de Propuesta Ciudadana, CBC. Recuperado el 2 de marzo de 2010, de :

http://www2.congreso.gob.pe/sicr/cendocbib/con4_uibd.nsf/587B13F804A8519505257C230 06D37BF/\$FILE/gasto_publico_canon_Peru.pdf

Herrera, J. (2002). "Pobreza y desigualdad en el área andina. Elementos para un nuevo paradigma. Introducción. Bulletin de l'Institut Français d'Études Andines, 31 (3), pp.413428.

Huaita Alfaro, A. M. (2012) "Ecoturismo y desarrollo humano: el caso de una asociación privada con la comunidad de infierno ", Turismo y Patrimonio, no 7, pp. 23-31.

INEI-Instituto Nacional de Estadística e Informática (2015). Mapa de pobreza distrital y provincial 2013, Lima: INEI. Recuperado el 6 de octubre de 2015 de: https://www.inei.gob.pe/media/MenuRecursivo/publicaciones_digitales/Est/Lib1261/Li bro.pdf

INEI-Instituto Nacional de Estadística e Informática (2016). Encuesta Demográfica y de Salud Familiar - ENDES, 2015 - Departamento de Cusco, Lima: INEI. Recuperado el 2 de octubre de 2016 de: https://www.inei.gob.pe/media/MenuRecursivo/publicaciones_digitales/Est/Lib1356/

INEI-Instituto Nacional de Estadística e Informática (2017). Evolución de la pobreza monetaria 2007-2016. Informe Técnico. INEI. Recuperado el 20 de mayo de 2017.

https://www.inei.gob.pe/media/cifras_de_pobreza/pobreza2016.pdf

INEI-Instituto Nacional de Estadística e Informática (2018). Evolución de la pobreza monetaria 2007-2017. Informe Técnico. INEI. Recuperado el 30 de abril de 2018.

https://www.inei.gob.pe/media/cifras_de_pobreza/informe_tecnico_pobreza_monetaria_20072017.pdf

IPE-Instituto Peruano de Economía. (2015).Logros y retos del desarrollo económico y social de Cusco. Recuperado el 12 de octubre de 2017 de file:/ / C:/Users/usuario/Downloads / 285414562-Logros-y-Retos-Del-DesarrolloEconomico-y-Social-de-Cusco-2015.pdf

IPE-Instituto Peruano de Economía. (2018).Perspectivas de la economía y la competitividad de Perú y Cusco. Recuperado el 20 de enero de 2018 de

http://www.ipe.org.pe/portal/wp-content/uploads/2018/02/2018-01-29-Cusco-UN-SanAntonio-de-Abad.pdf

La República (30 de abril 2018) "Los herederos de la pobreza en Cusco". La República. Recuperado el 30 de abril 2018, de

https://larepublica.pe/politica/1235005-herederos-pobreza-cusco

Martorell Carreño, A. (2000). Machu Picchu: Patrimonio cultural en peligro. Lima: Editorial Malze.

Matuk, F. (2010). “¿Qué pobreza preferirá García en su último discurso de 28

de julio?”. Recuperado el 20 de julio de 2010 de https://29x55.wordpress.com/tag/pobrezaalimentaria/

MINCETUR -Ministerio de Comercio Exterior y Turismo. Estadísticas en línea: Consulta octubre de 2017. http://www.mincetur.gob.pe

MTPE-Ministerio de Trabajo y Promoción del Empleo. (2013). Estudio de la actividad turística: Identificación de las ocupaciones demandadas a nivel nacional. Lima: MTPE.

OMT-Organización Mundial de Turismo. (2004). Turismo y atenuación de la pobreza. Recomendaciones para la acción. Madrid: OMT 
OTP-Observatorio Turístico del Perú. BADATUR estadisticas, recuperado de: http://www.observatorioturisticodelperu.com

Pérez Galán, B. (2012). "Retóricas del turismo y desarrollo en Los Andes: La Red de Turismo Rural Comunitario Pacha Paqareq, Perú”. En Asensio, R.H. y Pérez Galán, B. (eds.) ¿El turismo es cosa de pobres?: Patrimonio cultural, pueblos indigenas y nuevas formas de turismo en América Latina (171-200). Tenerife y Lima: Asociación Canaria de Antropología; Pasos; Instituto de Estudios Peruanos.

Pérez Galán, B., y Fuller, N. (2015). Turismo rural comunitario, género y desarrollo en

comunidades campesinas e indigenas del Sur del Perú. Quaderns de l'Institut Català d'Antropologia, sèrie monogràfics, 31, pp. 95-119.

PNUD-Programa de las Naciones Unidas para el Desarrollo. (2011). Desarrollo centrado en las personas. Informe anual 2010/2011. Nueva York: PNUD

Roca Rey, I., y Rojas, B. (2002). "Pobreza y exclusión social: una aproximación al caso peruano", Bulletin de l'Institut Français d'Études Andines. Pobreza y desigualdad en el área andina, 31 (3), PP. 699-724.

Sánchez Guzmán, E.; Muennekhoff, B. y Ricard Lanata, X. (2006). Propuesta para el gobierno regional 2007-2010, Lima: CIES / CBC.

Sariego López, I. (2014). "Espacios turísticos rurales para el desarrollo sostenible: El turismo rural comunitario en el Perú", Turismo y Patrimonio, 8, pp.47-61

Sen, A. (1999). Nuevo examen de la desigualdad. Madrid: Alianza Editorial.

Sen, A. (2000). Desarrollo y libertad. Barcelona: Editorial Planeta.

Sen, A. y Kliksberg, B. (2007). Primero la gente. Una mirada desde la ética del desarrollo a los principales problemas del mundo globalizado. Barcelona: Ediciones Deusto.

Stronza, A. (2008). Through a new mirror: Reflections on tourism and identity in the Amazon. Human Organization, 67(3), pp. 244-257.

Tello Rozas, S. y Paredes Izquierdo, J. C (2002) " Turismo, pobreza y desarrollo. Una propuesta de análisis para América Latina ", Revista Alcuth, no 1, pp. 29-51.

Terry, C. (2017). Turismo Rural Comunitario: ¿una alternativa para las comunidades andinas? El caso del agro-ecoturismo del Parque de la Papa (Cusco, Perú). En Gascón, J. y Milano, C. (Coord.) El turismo en el mundo rural. ¿Ruina o consolidación de las sociedades campesinas e indigenas? Tenerife y Barcelona: PASOS; RTPC; Foro de Turismo Responsible; Ostelea.

Urbano, H. (2002). "El hecho turístico: la construcción de una sintaxis metodológica para América Latina". Alcuth, 1/2002, 63-76

Urbano H.; Izaguirre M. y Marsano, J. (2010). La brecha entre oferta y demanda en sector de los recursos humanos en el espacio hotelero de la ciudad de Cuzco. Lima: Observatorio Turístico del Perú.

Urry, J. (2004). La Mirada del turista. Lima: Universidad de San Martín de Porres.

Vásquez Huamán, E., et al. (2004). Los desafios de la lucha contra la pobreza extrema en el Perú. Lima: Universidad del Pacífico.

Vásquez Huamán, E. (2012). El Perú de los pobres no visibles para el Estado: La inclusión social pendiente a julio del 2012, Documento de discusión, $\mathrm{n}^{\circ} \mathrm{DD} / 12 / 04$, Lima: Centro de investigación, Universidad del Pacifico.

Verdera, F. (2007). La pobreza en el Perú. Un análisis de sus causas y de las políticas para enfrentarla, Lima: IEP.

Zan, L. y Lusiani, M. (2011). "Managing Change and Master Plans. Machu Picchu Between Conservation and Exploitation". En Archaeologies: Journal of the World Archaeological Congress, Forthcoming. 


\section{HOW TO CITE THIS ARTICLE IN BIBLIOGRAPHIE}

Figueroa Pinedo, J. (2018): Desarrollo turístico y pobreza. El caso del cuzco, Perú Rotur. Revista de Ocio y Turismo, 12(2): 60-79, http://www.rotur.es, ISSN: 1888-6884 